\title{
A Mobile Application for Controlling Domestic Gas Cylinders Remotely
}

\author{
Wafaa M. Shalash, Salha Al-Behairi, Nada Al-Qahtani, \\ Mashael Al-Muzaini, Bayan Sharahili, and Aisha Alawi \\ Information Technology Department, King Abdul Aziz University \\ P.O. Box 42808, Jeddah 21551, Saudi Arabia \\ Wafaa1@yahoo.com
}

\begin{abstract}
The domestic gas cylinders or cooking gas are considered as the source of energy commonly used at homes but, the potential for a serious accident such as gas leak from organizations or flow valves if the gas cylinder or its attachments are not treated properly or simply if the user forgot to close the gas before leaving home. The current project aims to develop a mobile application in order to control the gas cylinder remotely by mobile application in an effective way. The system consists of two parts. A specially designed controller connected to the gas cylinder organizer and an android mobile application to control the cylinder remotely through it. The main functions of this application are, controlling one or more domestic gas cylinder remotely, sending an audio alarm to the user if he leave while the gas cylinder opened and close it, providing an alarm if there is a gas leakage and close it and finally if the system fail to close it due to any reason it call the civil defense.
\end{abstract}

Keywords: Intelligent home, gas remote control, GSM, PIC controller, Android application.

\section{$1 \quad$ Introduction and Related Works}

The world has seen a great development and interest in intelligent home application and products. As the standard of living improves, people focus more on the home safety and the warehouse safety, and the demand of the protection on the gas leakage and the fire in the room higher and higher [1].

Smart homes contain multiple, connected devices such as home entertainment consoles, security systems, lighting, access control systems and surveillance. Intelligent home automation system is incorporated into smart homes to provide comfort, convenience, and security to home owners [2-4]. Home automation system represents and reports the status of the connected devices in an intuitive, user-friendly interface allowing the user to interact and control various devices with the touch of a few buttons. Some of the major communication technologies used by today's home automation system include Bluetooth, WiMAX and Wireless LAN (Wi-Fi), Zigbee, and Global System for Mobile Communication (GSM)[5]. All GSM is one of the most widely used cellular technologies in the world $[6,7]$. With the increase in the number 
of GSM subscribers, research and development is heavily supported in further investigating the GSM implementation [5].

Among the cellular technologies, GSM network is preferred for the communication between the home appliances and the user due to its wide spread coverage $[6,7]$ which makes the whole system online for almost all the time. Another advantage of using the GSM network in home automation is its high security infrastructure, which provides maximum reliability whereby other people cannot monitor the information sent or received. Hence, this research work implements DTMF based control for home appliances using the GSM architecture in order to provide remote control to home gas cylinder safely.

\section{System Architecture}

The proposed system consists mainly of two parts hardware and software. The block diagram of the proposed GSM base system is shown in figure1.

\subsection{Hardware}

The hardware first part contains mainly of PIC16F886 microcontroller circuit which control the gas valve. The microcontroller is managed using DTMF and GSM base technology as it contains mobile modem and SIM card. The second part is the flammable gas sensor (MQ- 2) which is attached to the circuit and finally the gas control valve attached to a special controller to open and close it. The DTMF IC works as an interface between the GSM modem and the PIC microcontroller. Figure 1 shows a general layout of the system. Figure 2 shows the circuit diagram and figure 3 shows the prototype of the proposed system hardware. Figure 4 shows the used gas sensor.

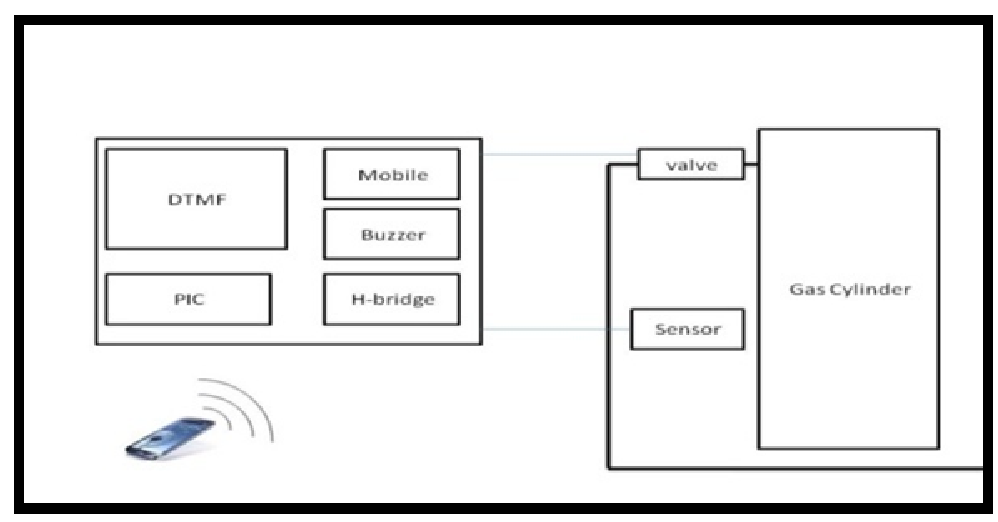

Fig. 1. Shows a general layout of the system 


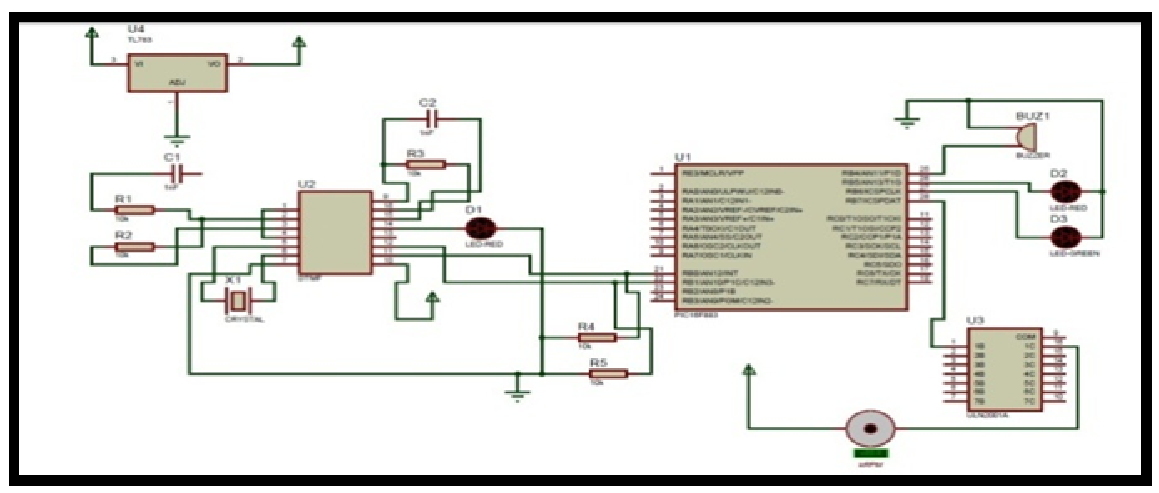

Fig. 2. Main controller circuit diagram

Regarding to figure 1 the main components are:

1. PIC (Peripheral Interface Controller), is the system's processor which has been programmed to read the sensor and issuing Software commands.

2. DTMF (Dual Tone Multi-frequency), which is dedicated to the reception of sound waves from mobile and convert it to digital

3. Buzzer which is responsible for determining resonance

4. The sensor which is testing if there is a leakage

5. The valve which is responsible for closing and opening the gas cylinder.

6. Data SIM-Card using the Global System for Mobile (GSM) to make a cell phone call with the application installed on an android system.

7. H-bridge (electronic circuit) which is used for the electrical voltage to prevent reflection of electric current.

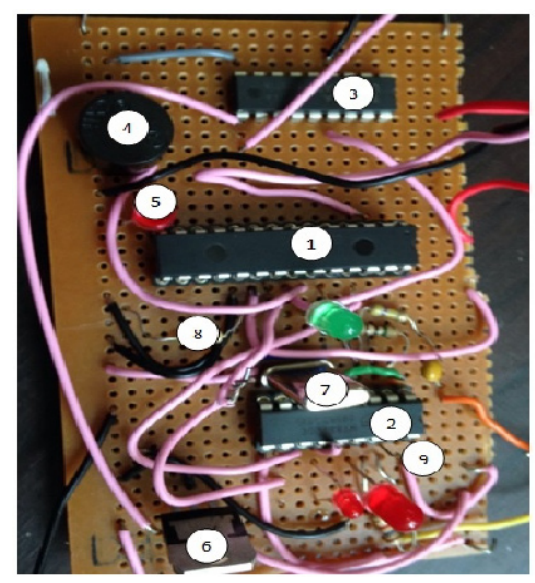

\begin{tabular}{|r|c|}
\hline & Elements \\
\hline 1 & Microcontroller \\
\hline 2 & DTMF \\
\hline 3 & ULN \\
\hline 4 & Buzzer \\
\hline 5 & LED \\
\hline 6 & Voltage Regulator \\
\hline 7 & CRYSTAL \\
\hline 8 & Resistor \\
\hline 9 & Capacitor \\
\hline 1 & MQ-2 gas sensor \\
\hline
\end{tabular}

Fig. 3. The prototype of the proposed system hardware 


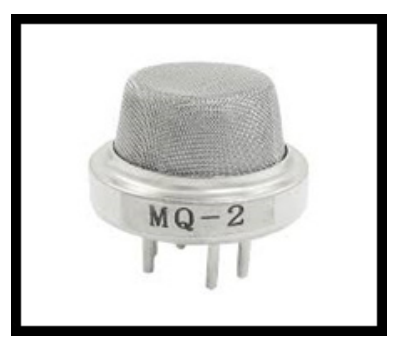

Fig. 4. MQ-2 gas sensor for flammable gas

\subsection{Software}

The android based software package is designed to enable user to control one or more domestic gas cylinder remotely by, sending an audio alarm to the user if he leaves while the gas cylinder is opened and close it, providing an alarm if there is a gas leakage and close it and finally if the system fail to close it due to any reason it call the civil defense.

The diagram level zero (figure 5)shows that the system takes his input from: users and make some processing then you can see the output on the gas that could be turn on or off according the command and the user can see the output of the processing as graphs.

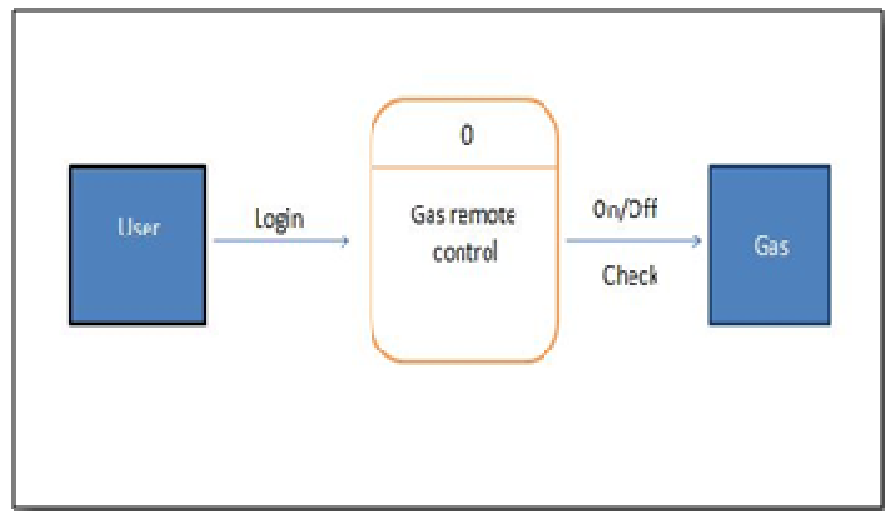

Fig. 5. Data flow diagram (level 0)

Figure 6 shows the data flow diagram (level 1) of the mobile application. It shows the interaction between entities, data base and processes. It shows the source of each command and data and its direction. The user can access user_personal_ info, and the gas _ info to sore and remove data. The user can access the gas_ info to store his gas information where the user accesses them to retrieve it and then control gas. 


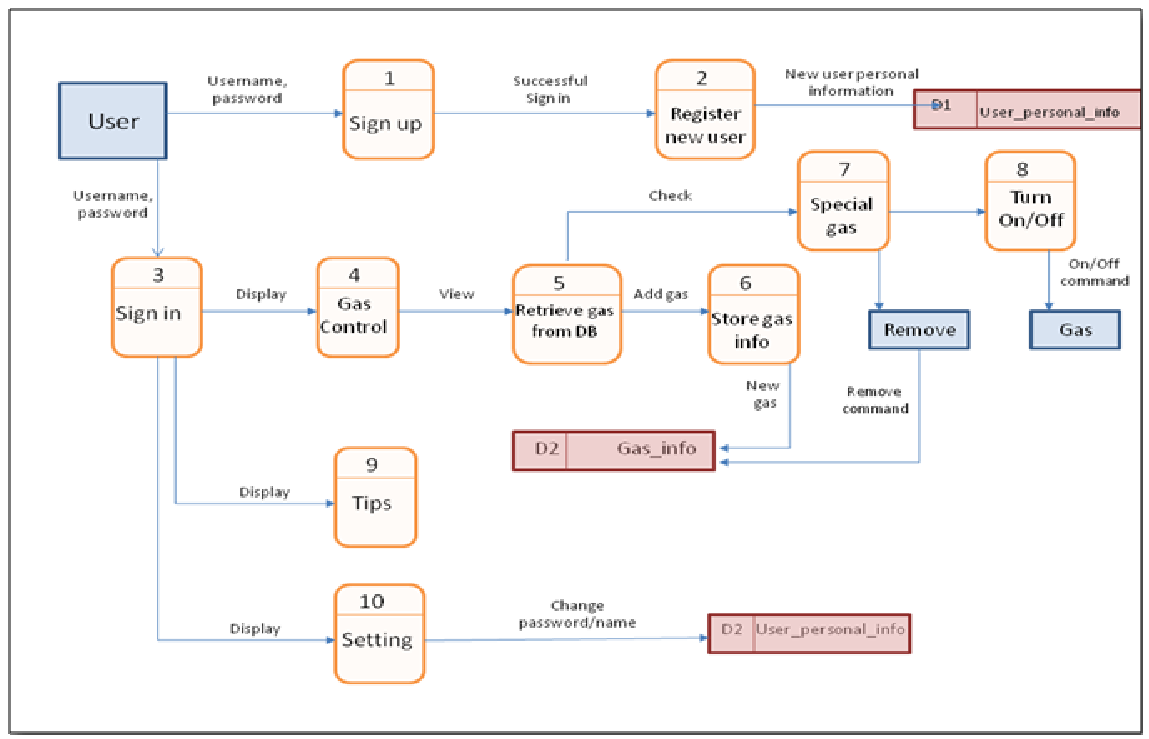

Fig. 6. Data flow diagram level1

The following figures $(7-12)$ show the designed GUI of the system which is designed as simple as possible in order to make its critical function easy for the user. A well designed usability test has been performed in order to test the efficiency of the designed GUI.

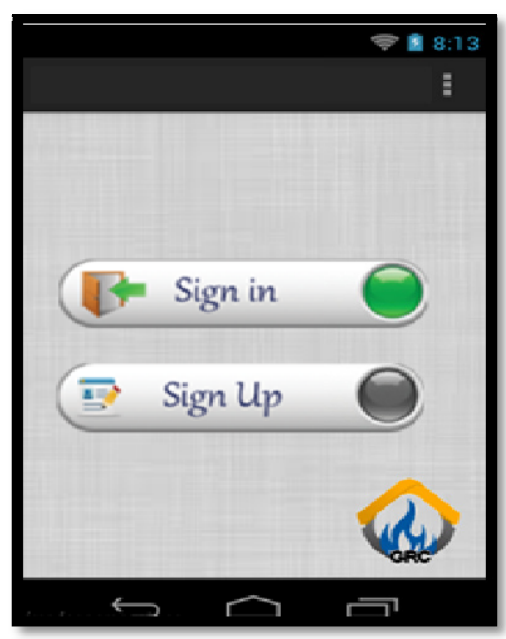

Fig. 7. Login/ sign up interface

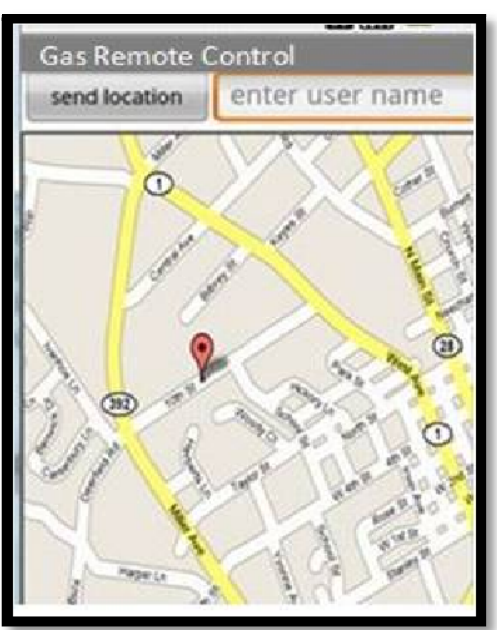

Fig. 8. Set location 


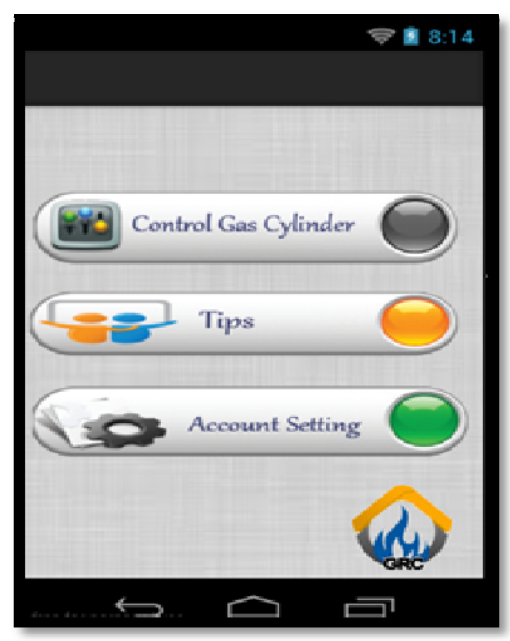

Fig. 9. Main Menu interface

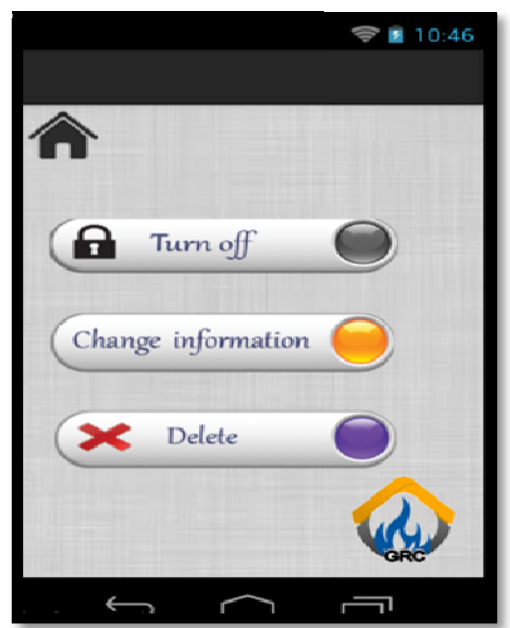

Fig. 11. Turn the gas cylinder on or off screen

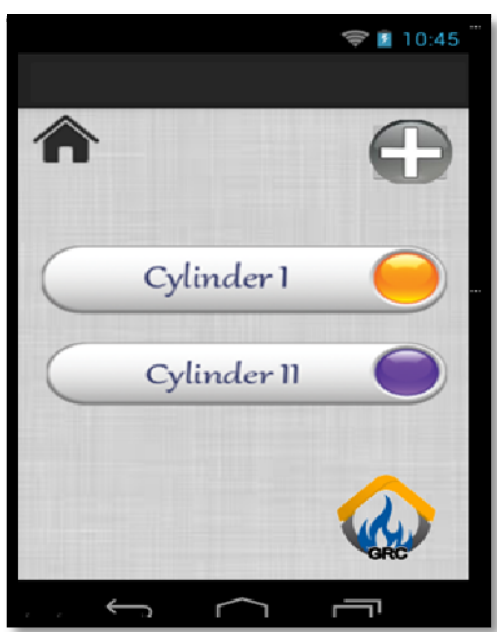

Fig. 10. Control cylinder interface

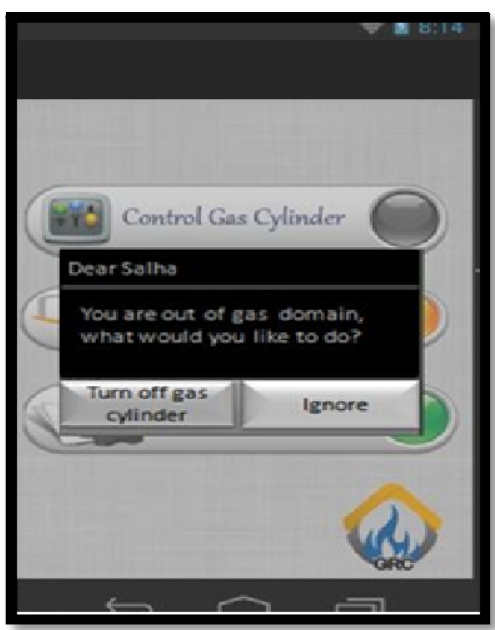

Fig. 12. Notification the popup window

\section{$3 \quad$ Usability Test and Results}

Before performing the test, the test general goals that will be tested have been decided and the chosen tasks depending on those goals. Each task will be given to the user and the user action and comments will be observed as they can gain results that help in better design choices. 


\subsection{Participant}

They conducted the test on ten user all of them are educated and their age between 20 and 35 year old. Users have experience in using mobile application.

\subsection{Task Scenarios}

1. User has six tasks to do:

2. Add new gas cylinder

3. Change id and name gas Cylinder

4. Remove gas cylinder

5. Turn On/Off gas cylinder

6. Tips

7. Change account information

Table 1. Tasks correct path

\begin{tabular}{|c|c|}
\hline Task No. & Correct Path \\
\hline Task\#1 & log in => Control gas cylinder $=>$ Add new gas cylinder \\
\hline Task\#2 & $\begin{array}{l}\log \text { in } \Rightarrow \text { Control gas cylinder }=>\text { Chose gas cylinder } \Rightarrow \\
\text { Change id and name of gas cylinder }\end{array}$ \\
\hline Task\#3 & $\begin{array}{l}\log \text { in }=>\text { Control gas cylinder }=>\text { Chose gas cylinder } \Rightarrow \\
\text { Remove gas cylinder }\end{array}$ \\
\hline Task\#4 & $\begin{array}{l}\text { log in }=>\text { Control gas cylinder }=>\text { Chose gas cylinder } \Rightarrow \text { Turn } \\
\text { On/Off gas cylinder }\end{array}$ \\
\hline Task\#5 & $\log$ in $=>$ Tips \\
\hline Task\#6 & $\log$ in $=>$ Setting account $=>$ Change user name and password \\
\hline
\end{tabular}

\subsection{Preparing Tasks Resources}

Time: 25 minutes

Place: They decided to conduct the test at the university, some others was at home.

\subsection{Performance Measures}

1. Time to finish each task

2. Number of clicks

3. Number of wrong clicks

4. Subjective measures:

These measures are participants' perceptions, opinions and judgments. So the developers need to take their rating.

1. Ease of use

2. Clarity of labels and button names 
Table 2. The three level of criteria

\begin{tabular}{|c|c|c|c|}
\hline Criteria & Excellent & Acceptable & Unacceptable \\
\hline \multicolumn{4}{|c|}{ Task\#1 : Add new gas cylinder } \\
\hline $\begin{array}{l}\text { Time to finish } \\
\text { the task } \\
\text { ( in seconds) }\end{array}$ & 00:20:07 & 00:24:00 & 00:29:00 \\
\hline Number of clicks & 3 & 4 & 5 \\
\hline $\begin{array}{cc}\text { Number } & \text { or } \\
\text { wrong clicks } & \end{array}$ & 0 & 1 & 2 \\
\hline \multicolumn{4}{|c|}{ Task\#2: Change id and name gas Cylinder } \\
\hline $\begin{array}{l}\text { Time to finish } \\
\text { the task } \\
\text { (in seconds) }\end{array}$ & 00:21:00 & 00:25:00 & 00:30:00 \\
\hline Number of clicks & 4 & 5 & 7 \\
\hline $\begin{array}{cc}\text { Number } & \text { or } \\
\text { wrong clicks } & \end{array}$ & 0 & 1 & 2 \\
\hline \multicolumn{4}{|c|}{ Task\#3 : Remove gas cylinder } \\
\hline $\begin{array}{l}\text { Time to finish } \\
\text { the task } \\
\text { (in seconds) }\end{array}$ & 00:18:03 & 00:22:00 & $00: 24: 03$ \\
\hline Number of clicks & 4 & 5 & 7 \\
\hline $\begin{array}{cc}\text { Number } & \text { or } \\
\text { wrong clicks } & \end{array}$ & 0 & 1 & 2 \\
\hline \multicolumn{4}{|c|}{ Task\#4: Turn On/Off gas cylinder } \\
\hline $\begin{array}{l}\text { Time to finish } \\
\text { the task } \\
\text { (in seconds) }\end{array}$ & 00:18:03 & 00:22:00 & $00: 24: 03$ \\
\hline Number of clicks & 4 & 5 & 6 \\
\hline $\begin{array}{cc}\text { Number } & \text { or } \\
\text { wrong clicks } & \end{array}$ & 0 & 1 & 2 \\
\hline \multicolumn{4}{|l|}{ Task\#5: Tips } \\
\hline $\begin{array}{l}\text { Time to finish } \\
\text { the task } \\
\text { (in seconds) }\end{array}$ & 00:09:00 & 00:13:00 & $00: 16: 00$ \\
\hline Number of clicks & 2 & 3 & 4 \\
\hline $\begin{array}{cc}\text { Number } & \text { or } \\
\text { wrong clicks } & \end{array}$ & 0 & 1 & 2 \\
\hline \multicolumn{4}{|c|}{ Task\#6: Change account information } \\
\hline $\begin{array}{l}\text { Time to finish } \\
\text { the task } \\
\text { ( in seconds) }\end{array}$ & 00:26:00 & 00:30:00 & 00:30:00 \\
\hline Number of clicks & 3 & 4 & 5 \\
\hline $\begin{array}{cc}\text { Number } & \text { or } \\
\text { wrong clicks }\end{array}$ & 0 & 1 & 2 \\
\hline
\end{tabular}




\section{The Levels of Criteria Are Established}

1. Excellent; This means the program is easy to use according to the performance in this task.

2. Acceptable: This means the user is satisfied with this level performance on this task.

3. Unacceptable : If user encounters problems when performing the task.

Table 3. Usability test sammary

\begin{tabular}{llllllllllllllll}
\hline Task & User1 User2 & User3 & User4 & User5 & User6 & User7 & User8 & User9 & User10 & Total & $\begin{array}{c}\text { Average } \\
\text { Task } \\
\text { performance }\end{array}$ \\
\hline Task1 & 4 & 3 & 3 & 3 & 3 & 3 & 4 & 3 & 5 & 3 & 34 & 3.4 & Excellent \\
Task2 & 5 & 5 & 5 & 6 & 6 & 5 & 4 & 4 & 6 & 5 & 51 & 5.1 & Acceptable \\
Task3 & 5 & 4 & 6 & 4 & 5 & 6 & 5 & 6 & 5 & 5 & 51 & 5.1 & Acceptable \\
Task4 & 5 & 4 & 4 & 4 & 4 & 4 & 6 & 5 & 5 & 4 & 45 & 4.5 & Excellent \\
Task5 & 2 & 2 & 2 & 2 & 2 & 2 & 2 & 2 & 2 & 2 & 20 & 2 & Excellent \\
Task6 & 3 & 3 & 3 & 3 & 3 & 4 & 3 & 3 & 3 & 3 & 31 & 3.1 & Excellent \\
\hline
\end{tabular}

\section{Conclusion}

Recently intelligent home applications and products including remote controlling devices such as air-conditions heating and lighting are considered as a promising field needs more researches and products. We present an ongoing project to produce a home gas cylinder remote controlled system base on using GSM technology which provides high security and reliability to the system as it will make the system online almost all the time[]. The system also is dedicated to provide remote control for only flammable gas cylinder instead of controlling other home devices like many other applications which make it low cost companied with other solutions. The proposed system was implemented using PIC16F886 microcontroller and DTMF with the cooperation of GSM and an Android application which provides the gas cylinder remote. The system prototype was tested and the results shows a promising results.

\section{$5 \quad$ Future Work}

In future we are going to add many other features to the system such as:

- Schedule timers

- Cloud service allowing access via multiple devices

- Supports multiple IP cameras 


\section{References}

1. Tang, Z., Shuai, W., Luojun: Remote Alarm Monitor System Based on GSM and ARM. Procedia Engineering 15, 65-69 (2011)

2. Ahmad, A.W., Jan, N., Iqbal, S., Lee, C.: Implementation of ZigBee-GSM based Home Security Monitoring and Remote. In: Proc. 2011 IEEE 54th International Midwest Symposium on Circuits and Systems (MWSCAS), Seoul, pp. 1-4 (2011)

3. Begum, T., Hossain, M.S., Uddin, M.B., Chowdhury, M.S.H.: Design and development of activation and monitoring of home automation system via SMS through microcontroller. In: Proc. 2009 4th International Conference on Computers and Devices for Communication (CODEC 2009), Kolkata, pp. 1-3 (2009)

4. [4] Zhai, Y., Cheng, X.: Design of smart home remote monitoring system based on embedded system. In: Proc. 2011 2nd International Conference on Computing, Control and Industrial Engineering (CCIE), Wuhan, pp. 41-44 (2011)

5. Teymourzadeh, R., Ahmed, S.A., Chan, K.W., Hoong, M.V.: Smart GSM Based Home Automation System. In: 2013 IEEE Conference on Systems, Process \& Control (ICSPC 2013), Kuala Lumpur, Malaysia, December 13-15 (2013)

6. Gu, G., Peng, G.: The survey of GSM wireless communication system. In: Proc. 2010 International Conference on Computer and Information Application (ICCIA), Tianjin, pp. 121-124 (2010)

7. Mingming, G., Shaoliangshan, Huixiaowei, Sunqingwei: The System of Wireless Smart House Based on GSM and ZigBee. In: Proc. 2010 International Conference on Intelligent Computation Technology and Automation (ICICTA), Changsha, pp. 1017-1020 (2010) 